\title{
Velvet and Creeping Bentgrass Tolerance to Fenoxaprop
}

\author{
Gerald M. Henry and Stephen E. Hart ${ }^{1}$
}

Department of Plant Biology and Pathology, Rutgers, The State University of New Jersey, New Brunswick, NJ 08901

\section{Additional index words. Agrostis canina, Agrostis stolonifera}

\begin{abstract}
The tolerance of velvet bentgrass (Agrostis canina L.) to the herbicide fenoxaprop is not known. In greenhouse experiments velvet bentgrass cultivars SR7200 and Vesper had a much greater degree of tolerance to fenoxaprop at rates ranging from 0.01 to 0.30 $\mathrm{kg} \cdot \mathrm{ha}^{-1}$ relative to $\mathrm{L}-93$ creeping bentgrass (Agrostis stolonifera L.). SR7200 and Vesper were tolerant to fenoxaprop at $0.15 \mathrm{~kg} \cdot \mathrm{ha}^{-1}$ or lower and growth reductions did not exceed $10 \%$ at the highest fenoxaprop rate of $0.30 \mathrm{~kg} \cdot \mathrm{ha}^{-1}$. In contrast, growth reduction of L-93 creeping bentgrass was evident at the lowest application of fenoxaprop at $0.01 \mathrm{~kg} \cdot \mathrm{ha}^{-1}$ and increased as fenoxaprop rates increased, reaching as high $58 \%$ at $0.30 \mathrm{~kg} \cdot \mathrm{ha}^{-1}$. Field experiments were conducted in 2002 and 2003 to compare the tolerance of established SR7200 velvet bentgrass and Penn A-4 creeping bentgrass maintained at $3.2 \mathrm{~mm}$ to three sequential applications at 21 day intervals of fenoxaprop at $0.02,0.04$, and $0.07 \mathrm{~kg}^{-\mathrm{ha}^{-1}}$. Turf quality of SR7200 was equal to the untreated following all fenoxaprop applications except the third sequential application at $0.07 \mathrm{~kg} \cdot \mathrm{ha}^{-1}$. Penn A-4 turf quality was consistently reduced compared to the untreated following fenoxaprop applications of 0.04 and $0.07 \mathrm{~kg} \cdot \mathrm{ha}^{-1}$. Turf density of SR7200 was not affected by three sequential applications of fenoxaprop at 0.02 and $0.04 \mathrm{~kg} \cdot \mathrm{ha}^{-1}$ but was reduced by $8 \%$ at $0.07 \mathrm{~kg} \cdot \mathrm{ha}^{-1}$. Penn $\mathrm{A}-4$ turf density was reduced by 10 and $33 \%$ following three sequential applications of fenoxaprop at 0.04 and $0.07 \mathrm{~kg} \cdot \mathrm{ha}^{-1}$, respectively. Results from these studies showed that the velvet bentgrass cultivars were more tolerant to fenoxaprop, compared to the creeping bentgrass cultivars evaluated. Chemical names used: (+)-ethyl2-[4-[(6-chloro-2-benzoxazolyl)oxy $]$ p henoxy] propanoate (fenoxaprop). 3,5-pyridinedicarbothioic acid, 2-(difluoromethyl)-4(2-methylpropyl)-6-(trifluoromethyl)-S,S-dimethylester (dithiopyr).
\end{abstract}

Fenoxaprop is widely used postemergence in cool-season turfgrass species to selectively control a variety of summer annual grassy weeds, such as smooth crabgrass (Digitaria ischaemum Schreb. ex Muhl.), large crabgrass (Digitaria sanguinalis (L.) Scop.), and goosegrass (Eleusine indica (L.) Gaertn.). Although fenoxaprop is labeled for use in perennial ryegrass (Lolium perenne L.), tall fescue (Festuca arundinacea Schreb.), fine fescue (Festuca rubra L. and Festuca longifolia L.), kentucky bluegrass (Poa pratensis L.) and creeping bentgrass, the relative tolerance of these cool-season turfgrass species varies greatly to fenoxaprop.

Tall fescue, fine fescue, and perennial ryegrass have a high degree of tolerance to fenoxaprop relative to kentucky bluegrass and creeping bentgrass. Neal et al. (1990) reported that fenoxaprop applied at $0.20 \mathrm{~kg} \cdot \mathrm{ha}^{-1}$ and 0.40 $\mathrm{kg} \cdot \mathrm{ha}^{-1}$ caused no reduction in turfgrass quality of established tall fescue, chewings fine fescue (Festuca rubra L., ssp. commutate Gaud.), and perennial ryegrass. However, Bhowmik (1986) and Johnson (1994) observed stunting and discoloration of kentucky bluegrass following fenoxaprop applications of 0.14 and $0.28 \mathrm{~kg} \cdot \mathrm{ha}^{-1}$.

Received for publication 4 Mar. 2004. Accepted for publication 3 Apr. 2004. The authors gratefully acknowledge the financial support provided by the New Jersey Turfgrass Association and the Center for Turfgrass Science, Rutgers University.

${ }^{1}$ To whom reprint requests should be addressed; e-mail hart@aesop.rutgers.edu.
Several researchers have observed unacceptable levels of injury in the form of discoloration and stand thinning to creeping bentgrass following fenoxaprop applications of $0.28 \mathrm{~kg} \cdot \mathrm{ha}^{-1}$ to as low as $0.05 \mathrm{~kg} \cdot \mathrm{ha}^{-1}$ (Carroll et al., 1992; Dernoeden, 1987, 1989; Higgins et al., 1987; Shim and Johnson, 1992). The low degree of creeping bentgrass tolerance to fenoxaprop relative to the other cool season turfgrass species is reflected on the fenoxaprop label (Anonymous, 2003). Use rates on creeping bentgrass may not exceed $0.02 \mathrm{~kg} \cdot \mathrm{ha}^{-1}$ and sequential applications should be made at a minimum of 21 -d intervals. The bentgrass turf should be established for at least one growing season and maintained at a minimum cutting height of $0.64 \mathrm{~cm}$. Fenoxaprop should not be used on creeping bentgrass putting greens.

Despite the label limitations and low tolerance of creeping bentgrass to fenoxaprop, it is still widely used on golf courses to control weed escapes from applications of residual herbicides. In the northern U.S., fenoxaprop is extensively used on creeping bentgrass in areas that are continually reseeded such as tee boxes, and high traffic areas of the fairway due to it's limited soil residual relative to preemergence herbicides such as dithiopyr.

Another bentgrass species, velvet bentgrass, is often used in place of creeping bentgrass as a golf course turf in cool, moist, oceanic climates found predominantly in New England and the Pacific Northwest (Christians 1998; Turgeon 1996). Velvet bentgrasses are prostrate, stoloniferous grasses whose fine leaf texture and high shoot density lead to a lush, velvet-like appearance (DeFrance et al., 1952; Sprague and Evaul, 1930). Recently, there has been increased interest in using velvet bentgrass outside of these areas as researchers have noted excellent heat, drought, and low temperature tolerance relative to creeping bentgrass (Beard 1973; Brilman and Meyer 2000). Velvet bentgrass also performs well on acidic soils and in shaded areas compared to creeping bentgrass (North et al., 1934; Reid, 1932, 1933).

Fenoxaprop is currently not labeled for use on velvet bentgrass. No research has been conducted to evaluate the tolerance of velvet bentgrass to fenoxaprop. The objective of this research was to compare the tolerance of creeping bentgrass and velvet bentgrass to fenoxaprop.

\section{Materials and Methods}

Greenhouse experiments. SR7200 and Vesper velvet bentgrass, and L-93 creeping bentgrass were seeded at a rate of $73 \mathrm{~kg} \cdot \mathrm{ha}^{-1}$ into $10 \times 10-\mathrm{cm}$ plastic pots that were filled with a potting medium containing about $70 \%$ sphagnum peat moss, $20 \%$ \#3 grade horticultural vermiculite, and $10 \%$ horticultural perlite. The potting medium contained a proprietary starter fertilizer and had a $\mathrm{pH}$ of 6.5 . Following germination, plants were watered and fertilized as needed to promote optimum growth and maintained for two months at day/night temperatures of about $26 / 19^{\circ} \mathrm{C}$. Natural light was supplemented with artificial light at 400 $\mu \mathrm{mol} \cdot \mathrm{m}^{-2} \cdot \mathrm{s}^{-1}$ photosynthetic photon flux in a 12-h day. Plants were trimmed twice a week to a cutting height of $2.5 \mathrm{~cm}$ until herbicide application then allowed too grow naturally. Plants were treated with fenoxaprop (Acclaim Xtra 0.57 EW, Bayer Environmental Science, Durham, N.C.) at 0, 0.01, 0.02, 0.04, 0.07, 0.15 and $0.30 \mathrm{~kg} \cdot \mathrm{ha}^{-1}$ about 2 months after seeding. Treatments were applied with a track sprayer equipped with a $9504 \mathrm{E}$ spray tip delivering 374 $\mathrm{L} \cdot \mathrm{ha}^{-1}$ at $276 \mathrm{kPa}$. Following herbicide treatment greenhouse environmental conditions were maintained as previously described.

The experimental design was a randomized complete block with four replications per treatment. The experiment was conducted twice and the combined results presented. Visual estimates of herbicide injury on a scale of 0 (no injury) to 100 (complete desiccation) were taken 4 weeks after treatment. Clippings were harvested 4 weeks after treatment at a cutting height of $2.5 \mathrm{~cm}$ and oven dried at $75^{\circ} \mathrm{C}$ for at least five days and weighed. Dry weight data were converted to percent growth reduction by comparing dry weights in treated to untreated pots. All data were subjected to an analysis of variance using PROC ANOVA (SAS Institute Inc., Cary, N.C.) and subjected to linear regression analysis to determine the fenoxaprop rate required for $50 \%$ growth reduction $\left(\mathrm{GR}_{50}\right)$.

Field experiments. The experiment was conducted at the Rutgers University Horticulture Research Farm II in North Brunswick, N.J., in 2002 and 2003. The soil type was a Nixon loam (fine-loamy, mixed, semiactive mesic typic Hapludults) with a $\mathrm{pH}$ of 6.3 and organic matter content of $30 \mathrm{~g} \cdot \mathrm{kg}^{-1}$. The experiments 


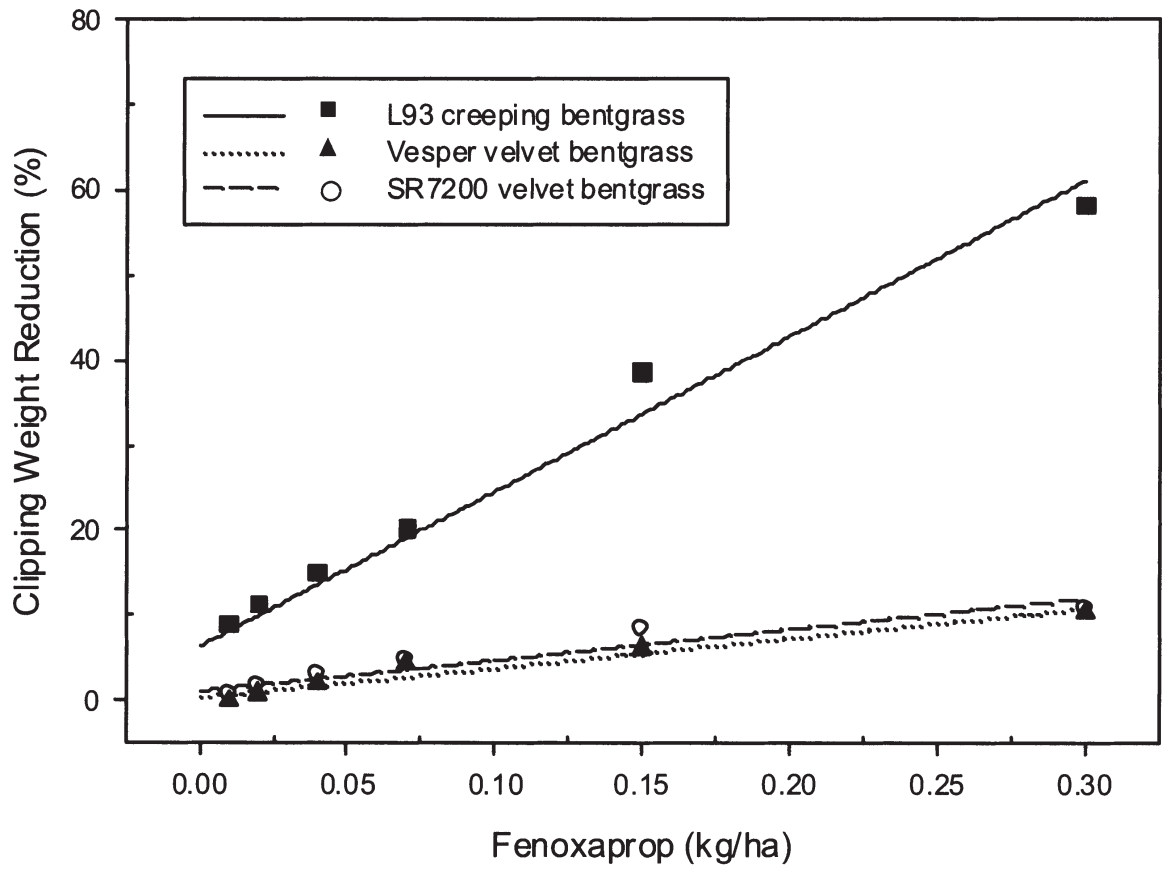

Fig. 1. Bentgrass clipping weight reduction at 4 weeks after treatment. Linear regression equations are: L93, y $=182.5 \mathrm{x}+6.32, R^{2}=0.89 ; \mathrm{SR} 7200, \mathrm{y}=36.4 \mathrm{x}+1.11, R^{2}=0.67$.Vesper, $\mathrm{y}=34.7 \mathrm{x}+0.40, R^{2}$ $=0.81$. The fenoxaprop rate required for $50 \%$ growth reduction $\left(\mathrm{GR}_{50}\right)$ was estimated as L-93=0.24 $\mathrm{kg} \cdot \mathrm{ha}^{-1}$; SR7200 and Vesper $>0.03 \mathrm{~kg} \cdot \mathrm{ha}^{-1}$.

Table 1. Turf quality ${ }^{\mathrm{z}}$ (TQ) of field grown SR7200 velvet bentgrass and Penn A-4 creeping bentgrass maintained to a height of $3.2 \mathrm{~mm}$ following three sequential applications of fenoxaprop.

\begin{tabular}{|c|c|c|c|c|c|c|c|}
\hline \multirow[b]{3}{*}{ Treatment } & \multirow{3}{*}{$\begin{array}{c}\text { Rate } \\
\mathrm{kg} \cdot \mathrm{ha}^{-1}\end{array}$} & \multicolumn{6}{|c|}{$\mathrm{TQ}^{\mathrm{x}}$} \\
\hline & & \multicolumn{2}{|c|}{ Application $1^{y}$} & \multicolumn{2}{|c|}{ Application 2} & \multicolumn{2}{|c|}{ Application 3} \\
\hline & & SR7200 & Penn A-4 & SR7200 & Penn A-4 & SR7200 & Penn A-4 \\
\hline Untreated & & $8.7 \mathrm{a}^{\mathrm{x}}$ & $8.0 \mathrm{a}$ & $8.8 \mathrm{a}$ & $8.0 \mathrm{a}$ & $8.6 \mathrm{a}$ & $7.9 \mathrm{a}$ \\
\hline Fenoxaprop & 0.02 & $8.5 \mathrm{a}$ & $7.5 \mathrm{a}$ & $8.8 \mathrm{a}$ & $7.4 \mathrm{~b}$ & $8.3 \mathrm{a}$ & $7.4 \mathrm{a}$ \\
\hline Fenoxaprop & 0.04 & $8.3 \mathrm{a}$ & $6.5 \mathrm{~b}$ & $8.8 \mathrm{a}$ & $6.9 \mathrm{~b}$ & $8.3 \mathrm{a}$ & $6.6 \mathrm{~b}$ \\
\hline Fenoxaprop & 0.07 & $8.2 \mathrm{a}$ & $5.7 \mathrm{c}$ & $8.5 \mathrm{a}$ & $5.3 \mathrm{c}$ & $7.8 \mathrm{~b}$ & $4.3 \mathrm{c}$ \\
\hline
\end{tabular}

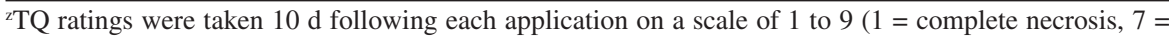
minimum acceptable level, 9 = dark green, uniformly dense turf).

yInitial applications were made on 11 June 2002 and 29 May 2003. Sequential applications at the same rates were made at $21 \pm 2$-d intervals.

${ }^{x}$ Means within each column followed by the same letter are not significantly different at the $5 \%$ level as determined by Fishers protected LSD test.

Table 2. Turf $\operatorname{cover}^{\mathrm{z}}$ of field grown SR7200 velvet bentgrass and Penn A-4 creeping bentgrass maintained to a height of $3.2 \mathrm{~mm}$ following three sequential applications of fenoxaprop.

\begin{tabular}{lccc}
\hline & Rate & \multicolumn{2}{c}{ Turf cover $(\%)^{\mathrm{z}}$} \\
\cline { 3 - 4 } Treatment & $\mathrm{kg} \cdot \mathrm{ha}^{-1}$ & SR7200 & Penn A-4 \\
\hline Untreated & & $100 \mathrm{a}^{\mathrm{y}}$ & $100 \mathrm{a}$ \\
Fenoxaprop & 0.02 & $100 \mathrm{a}$ & $95 \mathrm{ab}$ \\
Fenoxaprop & 0.04 & $98 \mathrm{ab}$ & $90 \mathrm{~b}$ \\
Fenoxaprop & 0.07 & $92 \mathrm{~b}$ & $67 \mathrm{c}$ \\
\hline
\end{tabular}

${ }^{2}$ Turf cover ratings were taken three weeks following the third application of fenoxaprop on a scale of 0 to $100(0=$ no turf cover and $100=$ complete uniform coverage).

${ }^{y}$ Means within each column followed by the same letter are not significantly different at the $5 \%$ level as determined by Fishers protected LSD test.

were conducted on SR7200 velvet bentgrass and Penn A-4 creeping bentgrass that were established in the fall of 2001 and maintained at a height of $3.2 \mathrm{~mm}$.

Fenoxaprop was applied at 0, 0.02, 0.04, and $0.07 \mathrm{~kg} \cdot \mathrm{ha}$ on 11 June 2002 and 29 May 2003 using a single nozzle $\mathrm{CO} 2$ backpack sprayer equipped with a 9504E spray tip delivering $374 \mathrm{~L} \cdot \mathrm{ha}^{-1}$ at $228 \mathrm{kPa}$. Initial application was followed by two sequential applications at the same rates at $21 \pm 2$-d intervals. Bentgrass species were mowed three times per week at $3.2 \mathrm{~mm}$ and irrigation was applied as needed to optimize bentgrass growth. Fertilizer (16 $\mathrm{NH}_{4}-4 \mathrm{P}_{2} \mathrm{O}_{5}-8 \mathrm{~K}_{2} \mathrm{O}$ ) was applied at a rate of $24.4 \mathrm{~kg}$ N/ha per month throughout the growing season.

The experimental design was a split plot with bentgrass species as the main plot and fenoxaprop treatment as subplots randomized within each bentgrass species. Individual plots were $1.2 \mathrm{~m}$ by $3.0 \mathrm{~m}$. Visual turf quality (TQ) ratings on a scale 1 to $9(1=$ complete necrosis, $7=$ minimum acceptable level, $9=$ dark green, uniformly dense turf) were taken $10 \mathrm{~d}$ after each application. Plots were also evaluated 3 weeks following the third application for bentgrass cover on a scale of 0 to $100(0=$ no turf cover and $100=$ complete uniform coverage $)$. All data were subjected to an analysis of vari- ance using PROC ANOVA and means were separated by the Fisher's Protected LSD test at the 0.05 probability level. The arcsine square root transformations of turf density data were also subject to ANOVA, but were not different from nontransformed data; therefore, the nontransformed data are presented.

\section{Results and Discussion}

Greenhouse study. Visual estimates of herbicide injury and dry weight reduction values were nearly identical in both greenhouse studies. Therefore, only the dry weight reduction data are presented (Fig. 1). Analysis of variance revealed a highly significant $(P<0.001)$ effect of bentgrass cultivar, fenoxaprop rate, and interaction between bentgrass cultivar and fenoxaprop rate. Due to the lack of fenoxaprop toxicity to the velvet bentgrasses, the rate required for $50 \%$ growth reduction $\left(\mathrm{GR}_{50}\right)$ could not be determined from the fitted regressions but would have exceeded the highest rate of 0.3 $\mathrm{kg} \cdot \mathrm{ha}^{-1}$ (Fig. 1). The $\mathrm{GR}_{50}$ value for L-93 was estimated at $0.24 \mathrm{~kg} \cdot \mathrm{ha}^{-1}$. SR7200 and Vesper were tolerant to fenoxaprop at $0.15 \mathrm{~kg} \cdot \mathrm{ha}^{-1}$ or lower and growth reductions did not exceed $10 \%$ at the highest fenoxaprop rate of 0.30 $\mathrm{kg} \cdot \mathrm{ha}^{-1}$. In contrast, growth reduction of L-93 creeping bentgrass was evident at the lowest application of fenoxaprop at $0.01 \mathrm{~kg} \cdot \mathrm{ha}^{-1}$ and increased as fenoxaprop rates increased, reaching as high $58 \%$ at $0.30 \mathrm{~kg} \cdot \mathrm{ha}^{-1}$.

Field study. Analysis of variance revealed no significant year by treatment interaction for all data so the combined results for 2002 and 2003 are presented. There was a highly significant $(P<0.001)$ effect of bentgrass cultivar, fenoxaprop rate, and interaction between bentgrass cultivar and fenoxaprop rate for all data.

Untreated bentgrass maintained high levels of TQ throughout the experiment with values ranging from 8.5 to 8.8 for SR7200 velvet bentgrass and 7.9 to 8.0 for Penn A-4 creeping bentgrass (Table 1). SR7200 velvet bentgrass treated with fenoxaprop maintained TQ levels that were equal to the untreated except following the third application at $0.07 \mathrm{~kg} \cdot \mathrm{ha}^{-1}$. SR 7200 TQ was still considered acceptable following this treatment but quality rating was reduced to 7.8 from 8.5. Penn A-4 creeping bentgrass TQ was consistently reduced following fenoxaprop applications of $0.04 \mathrm{~kg} \cdot \mathrm{ha}^{-1}$ and fell below the minimum acceptable level of 7.0. Increasing fenoxaprop application to $0.07 \mathrm{~kg} \cdot \mathrm{ha}^{-1}$ further reduced TQ of Penn A-4 to values that were approximately 30 to $45 \%$ below the untreated. Penn A-4 TQ treated with $0.07 \mathrm{~kg} \cdot \mathrm{ha}^{-1}$ was reduced to a greater extent as the number of application increased as evidenced by ratings of 5.7, 5.3, and 4.3 following the first, second, and third applications, respectively.

Reductions in TQ of Penn A-4 following the initial fenoxaprop were primarily attributed to necrosis and chlorosis of the treated turf. However, deterioration of the Penn A-4 turf stand became evident following the second application of fenoxaprop at $0.07 \mathrm{~kg} \cdot \mathrm{ha}^{-1}$. The turf cover of Penn A-4 was reduced by $10 \%$ and $33 \%$ compared to the untreated fol- 
lowing the third application of 0.04 and 0.07 $\mathrm{kg} \cdot \mathrm{ha}^{-1}$ fenoxaprop, respectively. Reduction in turf cover was also observed for SR7200 following the third application of $0.07 \mathrm{~kg} \cdot \mathrm{ha}^{-1}$ fenoxaprop. However, this reduction was only $8 \%$ compared to the untreated.

The phytotoxicity from multiple applications of fenoxaprop at 0.04 and $0.07 \mathrm{~kg} \cdot \mathrm{ha}^{-1}$ to Penn A-4 creeping bentgrass is consistent with injury observed in previous studies. Higgins et al. (1987) observed a decrease in creeping bentgrass turf color and density $28 \mathrm{~d}$ following single applications of fenoxaprop at rates ranging from 0.07 to $0.28 \mathrm{~kg} \cdot \mathrm{ha}^{-1}$. Shim and Johnson (1992) observed severe injury to creeping bentgrass from sequential fenoxaprop applications of 0.07 to $0.20 \mathrm{~kg} \cdot \mathrm{ha}^{-1}$, and creeping bentgrass turf quality did not fully recover for 3 months. Dernoeden $(1987,1989)$ reported that fenoxaprop caused unacceptable discoloration and a reduction in creeping bentgrass density when applied at $\geq 0.06 \mathrm{~kg} \cdot \mathrm{ha}^{-1}$, but no injury was observed when the rate was decreased to $0.04 \mathrm{~kg} \cdot \mathrm{ha}^{-1}$. However, Carroll et al. (1992) reported discoloration of creeping bentgrass turf following multiple fenoxaprop applications ranging from 0.03 to $0.05 \mathrm{~kg} \cdot \mathrm{ha}^{-1}$. Some of the differences in creeping bentgrass response to fenoxaprop between our study and previous studies may be due to changes in the fenoxaprop formulation, differences in cultivars and mowing heights, as well as varying environmental conditions between studies.

The results of these studies suggest that fenoxaprop can be used on velvet bentgrass with a higher degree of safety compared to creeping bentgrass. Application rates of fenoxaprop can be applied at 0.04 to $0.07 \mathrm{~kg} \cdot \mathrm{ha}^{-1}$ resulting in the potential for more consistent weed control and control of larger crabgrass and goosegrass plants. It is also important to note that the field study was conducted on bentgrass maintained at a mowing height of $3.2 \mathrm{~mm}$, which is typical of a golf course putting green surface. Fenoxaprop is not labeled for use on creeping bentgrass putting greens. However, the tolerance observed in these studies may allow for the use of fenoxaprop on velvet bentgrass putting surfaces. Additional field studies should be conducted to further characterize the tolerance of velvet bentgrass to fenoxaprop under varying environmental conditions and management regimes.

\section{Literature Cited}

Anonymous. 2003. Acclaim Xtra herbicide product label. Bayer Environ. Sci., Durham, N.C.

Beard, J.B. 1973. Turfgrass: Science and culture. Prentice-Hall, Englewood Cliffs, N.J.

Bhowmik, P.C. 1986. Fenoxaprop-ethyl for postemergence crabgrass control in kentucky bluegrass turf. HortScience 21:457-458.

Brilman, L.A. and W.A. Meyer. 2000. Velvet bentgrass: rediscovering a misunderstood turfgrass. Golf Course Mgt. 68(10):70-75.

Carroll, M.J., M.J. Mahoney, and P.H. Dernoeden. 1992. Creeping bentgrass (Agrostis palustris) quality as influenced by multiple low-rate applications of fenoxaprop. Weed Technol. 6:356-360.

Christians, N. 1998. Fundamentals of turfgrass man- agement. Ann Arbor Press, Chelsea, Mich.

DeFrance, J.A., T.E. Odland, and R.S. Bell. 1952. Improvement of velvet bentgrass by selection. Agron. J. 44:376-378.

Dernoeden, P.H. 1987. Phytotoxic effects of some herbicides applied to bentgrass. Proc. N.E. Weed Sci. Soc. 41:224-228.

Dernoeden, P.H. 1989. Mature creeping bentgrass and seedling kentucky bluegrass tolerance to fenoxaprop, p. 279-283. H. Takatoh (ed.). Proc. 6th Int. Turf. Res. Conf., Tokyo, Japan.

Higgins, J.M., L.B. McCarty, T. Whitwell, and L.C. Miller. 1987. Bentgrass and bermudagrass putting green turf tolerance to postemergence herbicides. HortScience 22(2):248-250.

Johnson, B.J. 1994. Herbicide programs for large crabgrass and goosegrass control in kentucky bluegrass turf. HortScience 29(8):876-879.

Neal, J.C., P.C. Bhowmik, and A.F. Senesac. 1990 Factors influencing fenoxaprop efficacy in coolseason turfgrass. Weed Technol. 4:272-278.

North, H.F.A. and T.E. Odland. 1934. Putting green grasses and their management. R.I. Agr. Expt. Sta. Bul. 245:1-44.

Reid, M.E. 1932. The effects of soil reaction on upon the growth of several different types of bentgrasses. Bul. USGA Green Sec. 12:196-212.

Reid, M.E. 1933. Effects of shade on the growth of velvet bent and Metropolitan creeping bent. Bul. USGA Green Sec. 13:131-135.

Shim, S.R. and B.J. Johnson. 1992. Response of creeping bentgrass to spring-applied herbicides. HortScience 27(3):237-239.

Sprague, H.B. and E.E. Evaul. 1930. Experiments with turfgrasses in New Jersey. N.J. Agr. Expt. Sta. Bul. 497. p. 1-55.

Turgeon, A.J. 1996. Turfgrass management. $4^{\text {th }}$ ed. Prentice-Hall, Englewood Cliffs, N.J. p. $1-406$. 